\title{
Research Overview on Training System of Logistics Management in Vocational Colleges Based on Open Mind*
}

\author{
Peng Shen \\ Hunan Modern Logistics College \\ Changsha, China
}

\begin{abstract}
Practical teaching is necessity for the training of technical and skilled talents in modern vocational education, and a training base is a place where practical teaching is done. In this article, an overview is given to training teaching from training course development, teaching mode, training base setup and more.
\end{abstract}

\section{Keywords—open type; teaching system; logistics management}

\section{INTRODUCTION}

Training is a teaching method used in vocational colleges to train students' abilities in practice, which is aimed to train technical and applied talents with comprehensive vocational quality through behavior guiding in teaching what students learn in vocational activities under national vocational skills standards. Such training has played an indispensable role in training students in vocational skills, intensifying perceptual knowledge and improving their abilities of applying knowledge and technology.

\section{SignifiCANCE OF Est ABLISHING AN OPEN TrAining SYSTEM}

It is a guarantee and way important and for vocational colleges in talents training to enhance training, build training bases and establish an perfect and open training system and for running college education. In recent years, with the enrollment scale expanded in vocational colleges in China, there are many problems arising as few facilities for training, inadequate time for training, lagging training methods as well as one-way activities for operating practice, all of which have become bottlenecks restricting effect of training teaching in vocational colleges. It will have a significant role for colleges to grasp how to make full use of expensive resources for training, change the management modes of training bases and establish an open training system, through which, there will be more opportunities for students in colleges to participate in the skill training, improve skill quality, awareness of innovation, creative spirit and development ability according to what they have learned, specialties and interests so as to enable vocational colleges to achieve goals of training applied and

*Creation of and Study on Open Train System in Colleges (ZJGB2016109, Teaching Reform and Research Program of College Vocational Education in Hunan Province) technical talents.

It is required to build a platform for students to learn and practice independently. An open training system will make the training room be a place which is completely open for practical skills training, it can not only give students an access to new technologies and skills in the industry during studying in colleges but make it feasible for students to learn independently in a "practical factory", complete training (experimental) projects so as to achieve an open teaching in training.

It is convenient to provide students with strong support to participate in skills competitions. A skill competition is an important way to train students in vocational colleges, which focuses on training students' abilities in practice and goals of employment, bringing a platform through which students can create and demonstrate skills of their own. To establish a training perfect and open can provide a strong support to vocational colleges which follows the principle "Competitions for Training, Integration of Competitions and Training, Intensifying Skills, Combination of Knowledge and Practice" and explores an efficient way for skills training through "Competition for Teaching, Competition for Learning, Integration of Teaching and Competition".

An open training system will make it possible for teachers to carry out scientific research and technical development, making it convenient for teachers especially new recruited teachers to make preparation for lessons, so that the new teachers can be familiar with all kinds of instruments and facilities for operation as soon as possible.

An open training system will make the training room available for teaching and scientific research, as well as serving the society, where enterprise employees and others can be trained there or cooperation between colleges and enterprises can be done for scientific research, new technologies can be promoted with certain service programs completed directly. With the training room used as a base research and development and the college-based training room used for vocational skills appraisal and training, it can bring both economic and social benefits.

It is necessary to exert functions of training instruments and apparatus to the maximum. Instruments and apparatus are a necessity important for improving the teaching level, whose 
values can be embodied through the number of students participating in training and the use frequency of the same. To build an open training system can maximize the use value of the instruments and apparatus, making it used in a high frequency within a limited time, working with full load, avoiding being idle. In addition, all kinds of resources can be shared to better the use so as to ensure the instruments and apparatus serve the teaching well.

It is possible to play a leading role in regional vocational education in the future. A perfect and open training system will make the training center fully exert its advantages in teaching, and build it into a universal system that can be used for practical teaching, scientific research, product R\&D according to conditions and possibilities. It can not only meet the needs of students in training, but also play a leading role in local higher vocational education, spreading to every corner of the province.

\section{ANALYSiS ON STATUS QUO OF OPEN TRAINING SySTEM IN CHINA AND FOREIGN COUNTRIES}

The training room is an important place where applied and technical talents are trained in vocational colleges, the training of practical ability and innovation has raised new requirements to not only the existing practical teaching systems, but also the building and management of training rooms. To complete what required by the syllabus within a limited time for experiments is far to meet the needs to train students, so it is very necessary to make the training rooms available for students in their spare time, which will help students make full use of the space and resources of the training room, carry out training and arrange time to learn independently, stirring the initiative and enthusiasm of students, in addition, teachers can also make full of resources in the training room to prepare for lessons, scientific research, technical development and more.

In recent years, with the vocational education regarded in the country, more and more investments have been used for vocational education gradually by authorities. Both the Central and provincial governments have increased investments in the building of practical teaching facilities and training bases in vocational colleges, most of which have also invested a lot of money to purchase practical teaching apparatus and instruments so as to strengthen the schooling strength of their own. Generally speaking, the conditions for practical teaching have been greatly improved in vocational colleges. The open training room can be put into practice only after it has been equipped with necessary conditions as teachers, training staff, training program, instruments and apparatus, environmental sites and management systems. Encouraged and directed by state policies, a great number of vocational colleges in recent year have begun to explore how to run training rooms, seek methods and modes for training rooms, with some training rooms open for management. However, due to the lack of a systematic and standard guide systems and effective rules and regulations, it always achieves little effect. For one, in recent three years, Hunan Modern Logistics College has greatly increased its investment in training rooms with more training rooms increased in number, but there are no systems to keep training rooms open in the college, in the past three years, the training rooms have only been keep open for students who participate in skill competitions, skills spot tests or training, yet the training rooms, when left unused, are not open to students or teachers, in addition, there are no standard management available to keep the training rooms open.

Vocational and technical education in developed countries grew with the process of industrialization, which has witnessed a history of hundreds of years. All countries have vocational and technical education models of their own which meet their national conditions, especially owning some experience successful in the building of training bases. The representative trainings of vocational education around the globe include Dual Education System mode in Germany, TAFE teaching mode in Australia and Teaching Factory mode in Singapore, all of the teaching modes focused on creating the same production environment as what in enterprises as possible as they can in colleges, where students are trained with vocational activities directed, as well as technical means as simulation and practice, besides, in spare time, all of the training rooms are kept open to students.

\section{A SUMMARY OF TEACHING RESEARCH ON LOGISTICS MANAGEMENT}

The Logistics Management is an application-oriented major, whose training teaching systems directly affect the quality of talents training. In order to grasp the development status of current Logistics Management in the field of practical training as a whole, the article gives a comprehensive summary from several points including training course development of logistics management, training teaching models, training bases and more.

\section{A. $R \& D$ of Training Courses}

Ji Zhongying et al. (2009) proposed that the development of the practical training course systems for Logistics Management in colleges should be based on productive training bases, which should achieve the integration of "theory + practice + experiment" courses. Cheng Ji (2010) discussed the courses development and reform from several points as course positioning and design, what to teach, teaching design, characteristics and innovation according to characteristics of the course "Storage and Distribution Training". Liu Chang (2010) proposed a five-step teaching method "pre-class preparation-cognition-observation-practice-summary" for logistics training teaching. Hu Yuanqing et al. (2012) and Xia Jianhui et al. (2013) developed a comprehensive training course of logistics. Wang Huimeng (2014) developed a training course system based on the work process. Wang Xiaoge (2014) thought that the building of training programs shall include three points: "single core course training program", "comprehensive training program" and "real training program for enterprises", raising suggestions from four points as bases building, training textbook development, appraisal mechanism, online course building.

\section{B. Studies on Practical Teaching Modes}

Zhong Jing et al. (2012) proposed a practical teaching mode including "selecting an appropriate training environment for teaching, bottom-up approach, system development training program, and skill assessment system that combines various 
forms through applying an action-oriented idea to the training teaching model. Zhu Jichuang (2013) tried and proposed a work flow training teaching mode, which defines roles of students, teachers, experts, and teaching management and more with training tasks assigned and the whole training process monitored. Duan Liyu (2013) proposed that the positioning of logistics talents training should be based on the analysis of demands for logistics talent, and the course setting should also be adjusted according to the positioning of talents training, and the logistics training courses supporting the course teaching should also go together with it optimized, and discussed the practical training from professional lectures, competitions and combination with practice. Zhu Xiting (2014) proposed a principle for campus training base organization "Combination of campus training and centralized training, integration of traditional learning and hardware operation and matching of campus training and off-campus training", giving methods to improving professional ethics as practical training program design, 6S management of training process according to vocational skills and quality requirements.

\section{Studies on Practical Training Bases}

Chen Xinhua et al. (2007) and Yang Liuyi (2013) thought that the innovation for building logistics training bases can be carried out from several points as "target management, mutual benefits, standard management, institutional innovation, teachers and textbooks". Xu Hong (2007) introduced the building of off-campus practice bases for Harbin Vocational and Technical College from three stages including cognitive training, teaching process training, and graduation training. Li Zhongguo (2008) thought that the logistics training base should have functions as "purchase, transportation, warehousing, inventory management, packaging, circulation \& processing, distribution, loading and unloading, and information processing" and more. Bai Shiqiang et al. (2010) proposed that it need to introduce the business work standards of logisticsbased enterprises to establish diversified training and teaching bases. Zhao Kai (2010) proposed three modes for the building of practical training bases as "campus training, schoolenterprise joint training, and school-school cooperation". Zeng Yikun et al. (2010) proposed plans of building logistics training bases including "logistics culture and sandbox deduction, warehousing and distribution, production logistics, logistics information, express delivery, chained operation, logistics business, etc." Li Xiaona (2012) proposed the modes of building training bases as "order training, joint building, school-school joint building and sharing and public training base". He Linghui (2013) thought measures as "seek fro governmental support, establishing a win-win and interactive base with innovation mechanism, and deepening the schoolrunning model "can be used to achieve the sustainable development of off-campus training bases. Zhu Wentao (2014) proposed the connotation, function and ideals to implement of building "In-school factory" training bases under the "dual-job $\&$ dual-role" model, which provides thought and experience for vocational colleges to introduce enterprises to colleges and establish "In-school factory".

\section{CONCLUSION}

In conclusion, scholars and experts have conducted studied on the existing practical training teaching of Logistics Management in China from different views, which provide references for colleges to implement logistics practical teaching, however, there are still no adequate researches and explorations with modularization used for system design of the whole training system of Logistics Management, which will become a hot issue to study for logistics teaching for some periods currently and in the future.

\section{REFERENCES}

[1] Ji Zhongying, etc., Development of a Logistics Management-Oriented Training Courses System in Vocational Colleges Based on Productive Training Base. Logistics Technology, Issue 10, 2009. (in Chinese)

[2] Zhong Jing et al. Research on Action-oriented Training Teaching Modes for Logistics Management in Vocational Colleges, Logistics Engineering and Management, Issue 3, 2012, p 215-216. (in Chinese)

[3] Ding Ming. Modular Design and Implementation for Training Teaching of "Logistics and Transportation Management", Journal of Yangzhou College of Education, Mar 2011, p88-90. (in Chinese)

[4] Zeng Yikun, etc. Discussion on the Building of Productive Training Base for Logistics Management, Logistics Technology, Sep 2010, p154157. (in Chinese)

[5] Lv Lili, Exploring Modular Teaching for Logistics Management in Vocational Colleges, China Market, Issue 10, 2010 p51-52. (in Chinese) 